\title{
THE FREQUEN CY OF LAW BREAKING AND COMPUlSORY HOSPITALIZATION AMONG THE Mentally Ill People in Katowice, Poland
}

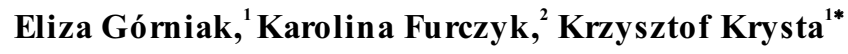 \\ ${ }^{1}$ Department of Psychiatry and Psychotherapy, Medical University of Silesia, Katowice, Poland \\ ${ }^{2}$ The Clinic of Psychiatry and Psychotherapy, Rostock University, Rostock, Germany
}

\begin{abstract}
It is a common belief that mental disorders are widely associated with dangerous, threat-posing behavior and law-breaking. The paper analyzes the problem of law-breaking by the mentally disordered. We performed an analysis of cases concerning compulsory psychiatric treatment or confinement in a medical institution on the grounds of mental incompetence to commit an offence or mental unfitness to stand the trial obtained from the court and the public prosecutor's office in Silesia from 2007 to 2009. 14 cases were analyzed. All the offenders were male, mean age was 44,6. All the offenders were diagnosed by psychiatrists, most of them with schizophrenia ( $n=10$ cases). Other diagnoses included paranoic syndrome $(n=1)$, bipolar affective disorder with manic episode $(n=1)$, schizoaffective disorder $(n=1)$, delusion syndrome $(n=1) .9$ out of 14 offenders were diagnosed prior to the offence, some of whom were also hospitalized $(n=5) .8$ of analyzed cases concerned use of violence, 3 concerned larceny, 2 concerned posing a threat to others' life or health and 1 concerned fraud. 2 of the offenders were previously sentenced for other offences. 12 of the offenders were compulsory treated by psychiatrists, 10 out of whom are still hospitalized at the time of writing this report. The small number of the cases analyzed (14 cases in the whole of a few thousands) suggests that mentally disordered persons do not break law often. There seems to be a higher risk associated with male gender, though. Also, the frequency of violent acts and offences committed despite previous treatment is disturbing.
\end{abstract}

Key w ord s: psychiatric disorders; law-breaking; violence

\section{INTRODUCTION}

It is a common belief that the mentally ill persons are violent, unpredictable and that they often pose a threat to others health and safety. These widely held opinions contribute to creating and reinforcing stigma attached to mental illness (Filipovits \& Farkas, 2008; Furczyk et al., 2011). The fact remains however that although mental illnesses are associated with increased risk of violent behavior, the association is not independent of modifying factors such as psychoactive substance abuse, history of family violence or other environmental stressors. Violent behavior may result in law-breaking attitudes (Fazel et al, 2009a; Elbogen Johnson, 2009; Fazel et al, 2009b). According to the Polish law a person who, as a result of psychiatric illness, mental retardation or other disturbance in psychic functions, has no ability to control his or her own behavior or to fully recognize its possible outcome,

*Correspondence to: Krzysztof Krysta, e-mail: krysta@mp.pl

Received November 30, 2011; accepted December 11, 2011; Act Nerv Super (Praha) 53(3-4), 146-9. 
although breaking the law, does not commit a crime (Polski Kodeks Karny, 2009). In such cases, if the behavior is destructive and socially harmful, and it is probable that this kind of conduct repeats, a person may be detained by the court's decision in an appropriate medical facility (Polski Kodeks Karny, 2009). Therefore a number of Polish court cases resulting in compulsory psychiatric treatment or confinement in a medical institution on the grounds of mental incompetence to commit a crime reflects the frequency of law breaking among the mentally ill.

The aim of this paper is to present and characterize the cases of law breaking by the mentally disordered in the city of Katowice. The legal qualification of committed offences and the results of legal proceedings with special emphasis on the aspect of violent behavior is described.

\section{METHOD}

For the purposes of this research, the records of all the cases from the years 2007 to 2009 were obtained from two Public Prosecutor's Offices and one District Court of Katowice. All the cases resulting in withdrawing the case on the grounds of the defendant's mental unfitnes s to stand the trial or in stating their mental incompetence to commit an offence were selected and analyzed.

\section{RESULTS}

Only 14 out of a few thousands of all cases were found to fit the research criteria. All the defendants were male. Their mean age was 44.6 years. At the moment of breaking the law, the youngest of the defendants was 21 , while the oldest was 72 years old. In the course of the legal proceedings all of the defendants were examined, observed and diagnosed by forensic psychiatrists. In most cases the final diagnosis was that of schizophrenia $(10$ cases, 9 out of which were diagnosed as paranoid schizophrenia, while the remaining 1 was schizophrenia combined with mental retardation). Other defendants were diagnosed with paranoid syndrome $(n=1)$, psychotic manic episode in the course of the bipolar affective disorder and concomitant alcohol dependence $(\mathrm{n}=1)$, schizoaffective disorder $(\mathrm{n}=1)$ and persistent delusion syndrome $(n=1)$. 9 out of 14 defendants had been treated and diagnosed by psychiatrists before breaking the law, however in three cases after the examination by the sworn experts the diagnoses were changed. Five out of these 9 defendants had also been hospitalized for psychiatric reasons before they broke the law, while the rest of them had only been treated as outpatients. Eight out of 14 analyzed cases were associated with violence and in most of them $(n=5)$ the violence was directed against the defendant's family members. As for the legal qualification of offences the defendants were accused of committing, the analysis revealed 8 cases of assault, 3 cases of larceny, 2 cases of posing a threat to others' life or health and 1 fraud. All cases of larceny involved objects of very small value, to give a vivid example, in one case a gold fish.

Two defendants had been accused of committing other crimes in the past, while for the rest of them the analyzed cases were their first contact with the law. As a result of the legal proceedings, twelve of the defendants were hospitalized and compulsory treated. Ten of them are still hospitalized at the time of writing this report.

\section{DISCUSSION}

According to the information found on the Katowice court's website, an average number of cases taking place each year in the offices which provided the data for this analysis reaches a few thousand. With this taken into consideration, the described 14 cases are found to 
constitute only a very small portion of the whole number of cases. This strongly contrasts with a popular image of violent, dangerous 'madmen' known from the media, influencing the way the mentally ill are seen by the society (Cutcliffe \& Hanningan, 2001).

Analyses conducted in other parts of Poland as well as abroad confirm this conclusion. Between 1997 and 2002 in the Polish city of Szczecin and the surrounding area there were 128 cases in which compulsory psychiatric treatment of the defendant was considered by the court. As a result of the legal proceedings, the court decided institutionalization in a medical facility was necessary in 85 of these cases (Kolasinski \& Korecka, 2004). In 1998 in Baltimore 14 out of 11497 defendants tried for different crimes pleaded insanity (Janofsky, Vandewalle, \& Rappeport, 1989). All of them were male, which seems to confirm differences between men and women in regards to criminal and violent behavior (Vaske et al., 2011)

The hereby presented analysis showed schizophrenia to be the most common disease diagnosed in the researched group of defendants, a fact which confirms that this disease is associated with aggressive and criminal behavior (Fazel et al., 2009a; Ran et al, 2010; Haller, Dittrich, \& Kocsis, 2004). In some of the described cases a matter of occasional alcohol abuse by the defendants was also raised. Alcohol abuse is known to increase the risk of aggressive behavior, mostly directed against the subject's own family members (Fazel et al., 2009b; Thompson \& Kingree, 2006). This kind of aggression was particularly common in the presented cases, which might be attributed both to the fact the defendants were mentally disturbed and to the coexisting problem of alcohol abuse.

Large number of mentally ill defendants presented in this paper had been diagnosed and treated by psychiatrists even before they broke the law. In these cases treatment did not prevent the disordered from committing the crime, although, as the related papers show, an early diagnosis, systematic and often visits to psychiatrist, as well as treating concomitant addictions all result in significant reduction of the risk of criminal behavior (Thompson \& Kingree, 2006; Van Dorn et al., 2011).

The presented analysis confirms the results of other similar research. Amongst the mentally disordered it is male patients diagnosed with schizophrenia who are especially inclined to present with criminal behavior. Violence in this group of patients is most often directed against their own family members, which also is related to alcohol abuse. The fact that a lot of crimes were committed in spite the fact that the defendants were being treated by psychiatrists suggests that the doctor-patient relationship needs continuous improvement and the scale of criminal risk has to be carefully and individually assessed in each and every case. Still, although there clearly is an association between mental disorders and aggressive or criminal behavior, the number of cases against the mentally ill seems minute when compared to the whole number of cases. There is an urgent need to start a public discussion concerning this matter to influence the whole society, an by this prevent stigmatization of the mentally disordered.

\section{REFEREN CES}

Cutcliffe Jr, \& Hanningan B. (2001) Mass media, 'monsters' and mental health clients: the need for increased lobbying. Journal of Psychiatric and Mental Health Nursing, 8, 315-21.

Elbogen EB, \& Johnson SC. (2009) The intricate link between violence and mental disorder: results from the National Epidemiologic Survey on Alcohol and Related Conditions. Archives of General Psychiatry, 66, 152-61.

Fazel S, Långström N, Hjern A, Grann M, \& Lichtenstein P. (2009) Schizophrenia, substance abuse, and violent crime. JAMA, 301, 2016-23.

Fazel S, Grann M, Carlström E, Lichtenstein P, Långström N. (2009) Risk factors for violent crime in Schizophrenia: a national cohort study of 13,806 patients. The Journal of Clinical Psychiatry, 70, 362-9.

Filipovits D, \& Farkas M. (2008) Violent behaviour and stigmatisation among psychiatric patients. Psychiatria Hungarica, 23, 420-9.

Furczyk K, Gorniak E, Skowronek R, Gajda M, Krysta K, \& Krupka-Matuszczyk I. (2011) The way young people see the mentalny ill: a questionnaire study. Psychiatria Danubina, 23, 46-49 
Haller R, Dittrich I, \& Kocsis E. (2004) How dangerous are patients with mental disorders? Wiener medizinische Wochenschrift, 154, 356-65.

Janofsky JS, Vandewalle MB, \& Rappeport JR. (1989) Defendants pleading insanity: an analysis of outcome. The Journal of A merican A cademy of Psychiatry and the Law, 17, 203-11

Kolasinski B, \& Korecka D. (2004) Internacja psychiatryczna- teoria i praktyka. Prokuratura i Prawo, 6, $135-156$

Polski Kodeks karny . Art. 31. § 1. and Art.94 § 1.(Dz. U. z dnia 2 sierpnia 1997 r)

Ran MS, Chen PY, Liao ZG, Chan CL, Chen EY, Tang CP, Mao WJ, Lamberti JS, \& Conwell Y. (2010) Criminal behavior among persons with schizophrenia in rural China. Schizophrenia Research, 122, 213-8

Thompson MP, \& Kingree JB. (2006) The roles of victim and perpetrator alcohol use in intimate partner violence outcomes. Journal of interpersonal violence, 21, 163-77.

Van Dorn RA, Andel R, Boaz TL, Desmarais SL, Chandler K, Becker MA, \& Howe A. (2011) Risk of arrest in persons with schizophrenia and bipolar disorder in a Florida Medicaid program: the role of atypical antipsychotics, conventional neuroleptics, and routine outpatient behavioral health services. The journal of clinical psychiatry, 72, 502-8.

Vaske J, Wright JP, Boisvert D, \& Beaver KM. (2011) Gender, genetic risk, and criminal behavior. Psychiatry research, 185, 376-81 